\title{
Research on the influence factors of College Students' participation in WeChat's marketing activities
}

\author{
Haiyan Liu ${ }^{a}$, Jiayi Zou ${ }^{b}$ and Ying Chen ${ }^{c}$ \\ Information Technology Institute, Jilin Agricultural University, Changchun 130117, China \\ ahaiyan_49@sohu.com, b727042974@qq.com, c384724725@qq.com
}

\begin{abstract}
WeChat marketing is based on a large number of WeChat users circle to form a new type of trading mode, college students as the main force of accepting new things and the carrier, has become the main WeChat user groups, has become the main participants in the WeChat marketing activities. This article through the questionnaire survey and statistical analysis of relevant data, to understand the situation of college students to participate in WeChat marketing activities, analyzes the influence of college students to participate in the influence factors and factors of WeChat marketing activities, in order to play the positive role of college students in the WeChat marketing activities, promote the development of WeChat marketing.
\end{abstract}

Keywords: College students; WeChat marketing; Participation degree; Influencing factors.

\section{Introduction}

WeChat marketing is the enterprise use WeChat platform, collect market information, and promote the enterprise products and propaganda enterprise culture a peer-to-peer marketing. College students as a product of science and technology, new things are most likely to receive groups, occupy a large market share in the WeChat marketing segments of the market, often at the center of the WeChat core circle of marketing, chain of WeChat plays a great role in driving growth. Therefore, WeChat marketing to seize the students, spur the development of this group by other market segments.

This paper adopts literature review and questionnaires, the study of consumer behavior theory to design the questionnaire based on the investigation of college students Changchun area using WeChat, analysis of students' awareness of the user Changchun area on WeChat marketing, based on statistical data of influence factors that affect the enterprise implementation of WeChat marketing of college students, providing theory support and effective suggestions for enterprises engaged in WeChat marketing practice.

\section{Research process}

\subsection{Object of study.}

This study selected the Changchun area from 985, 211, provincial colleges and private colleges in different batches of independent schools, including the Jilin Agricultural University, Northeast Normal University, Changchun Hospital of traditional Chinese Medicine University, Jilin University of Finance and economics, Jilin University, Changchun Guanghua School, as both literature and science, industry, agriculture and medicine, art and other disciplines from the background. One to four students in different grades.

\subsection{Research methods and data collection.}

Research team entered the university campus to random sampling survey of the research object, accumulative total 800 questionnaires, recycling questionnaire 800 , including invalid questionnaire, 80,720 valid questionnaires. By the statistics, the recycling effective questionnaire studies of 400 of the men and women the object of study for 320 people. For the raw data collected by sorting, cleaning and use ECCEL to classify the data analysis.

\subsection{Questionnaire design}

The questionnaire is divided into three parts, and the logical sequence of the basic information, the behavior information and the attitude information is carried out in depth. The basic information is 
mainly the basic situation of respondents, such as age, gender, grade, through the information statistics difference between different age, different grades and different gender exist in the use of WeChat users. Behavior information, including the reasons for the use of WeChat, WeChat use the online rate, the use of $\mathrm{WeChat}$ features, WeChat product experience, WeChat product purchase and the use of WeChat's public number and other issues. Through the investigation of the behavior information, it is able to understand the overall situation of the use of WeChat and the use of the characteristics of college students. The attitude information belongs to the questionnaire of senior information query module, including the tendency of WeChat, marketing products to push information, willingness to accept WeChat product experience and satisfaction, through the analysis of the attitude information, students can further WeChat marketing psychological characteristics and attitudes, more conducive to the enterprise according to the present college students the tendency will take the corresponding marketing measures.

\section{Analysis of research results}

\subsection{The influence of gender.}

In the survey sample, participated in the number of WeChat marketing for 244 people, including female college students for 160 people, accounting for $68.03 \%$ of the total number of WeChat marketing; male college students for 84 people, the total number of $31.97 \%$. Through the data analysis, the conclusion is: the proportion of female college students to participate in WeChat marketing is significantly higher than that of male college students. As can be seen, gender is one of the important factors that affect college students' participation in WeChat marketing. Because the female students have distinct characteristics in terms of consumption, relative to male students, most of them lack of rational consumer mentality, exhibit herd effect and strong psychological comparisons in the consumer, especially vulnerable recommendation, advertising media (Figure 1).

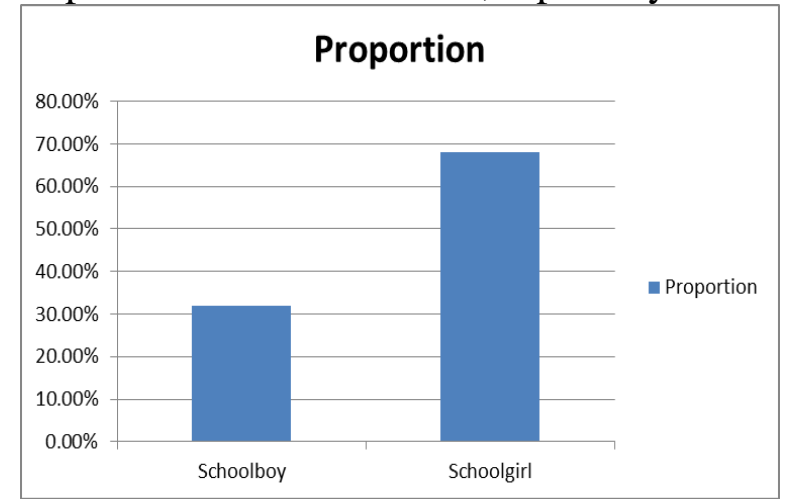

Fig. 1 Boys and girls contrast figure

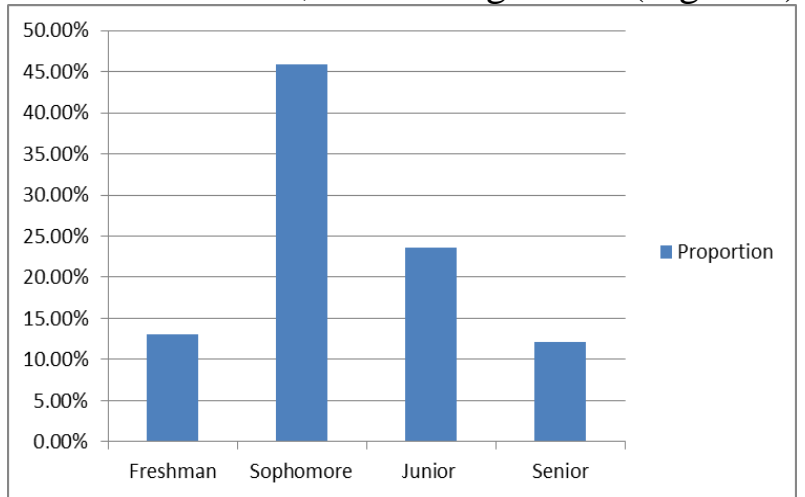

Fig. 2 Different grade scale figure

\subsection{The influence of the grade.}

Through investigation and analysis, the number of different grade students who participate in WeChat marketing and the proportion has the very big difference, As shown in figure 2, the largest number of sophomore students, accounting for $45.88 \%$ of the total. Junior year followed by accounts for $24.59 \%$ of the proportion of the total. Freshman and senior proportion is $13.11 \%$. Can see age is affect college students' participation WeChat marketing activity is one of the factors, but students groups in age section gap is small, do not represent the whole age difference influence on WeChat marketing participation, needs further research. Therefore, the enterprise in the WeChat marketing, can be targeted to the sophomore and the junior students of precision marketing, consumption ability of the potential depth of mining, will greatly improve the marketing effect.

\subsection{The influence of college students on the cost of living.}

As shown in figure 3, in Changchun area, to control the cost of living in 1000-2000 yuan of research object is notably on the high side, 1000-2000 yuan also more focus on college students' consumption ability of an area, accordingly, to participate in WeChat marketing number is also the 
highest proportion of students, the curve of the two basic convergence rate, is the cost of living to see disposable students groups of WeChat engagement one of the important factors that affect marketing activities. But is not the average disposable cost of living is higher, its participation WeChat marketing is more active, therefore, when making WeChat marketing enterprises, should be the Performance-to-price ratio is high and mid-range price products as the main sales type.

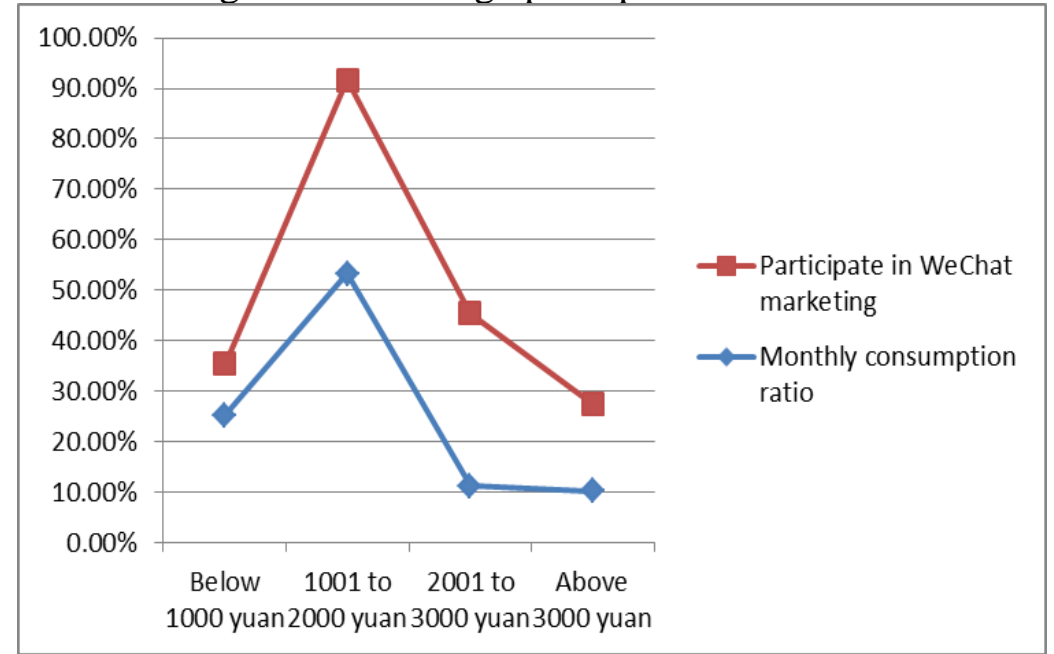

Fig. 3 Disposable and participation WeChat marketing contrast figure cost of living

\subsection{The influence of WeChat use time.}

Because the survey samples are selected using the WeChat college students, so that the use of WeChat in the sample interval was $100 \%$, but the use of time there is a huge difference, as shown in Figure 4, the total number of students every day to use the WeChat 2-5 in the long hours between the most, the highest frequency will also participate in WeChat marketing activities, according to the survey found that WeChat online longer students, the proportion in the WeChat marketing also increased, so that the frequent use of WeChat is one of the factors influencing college students participation in the marketing activities of WeChat.

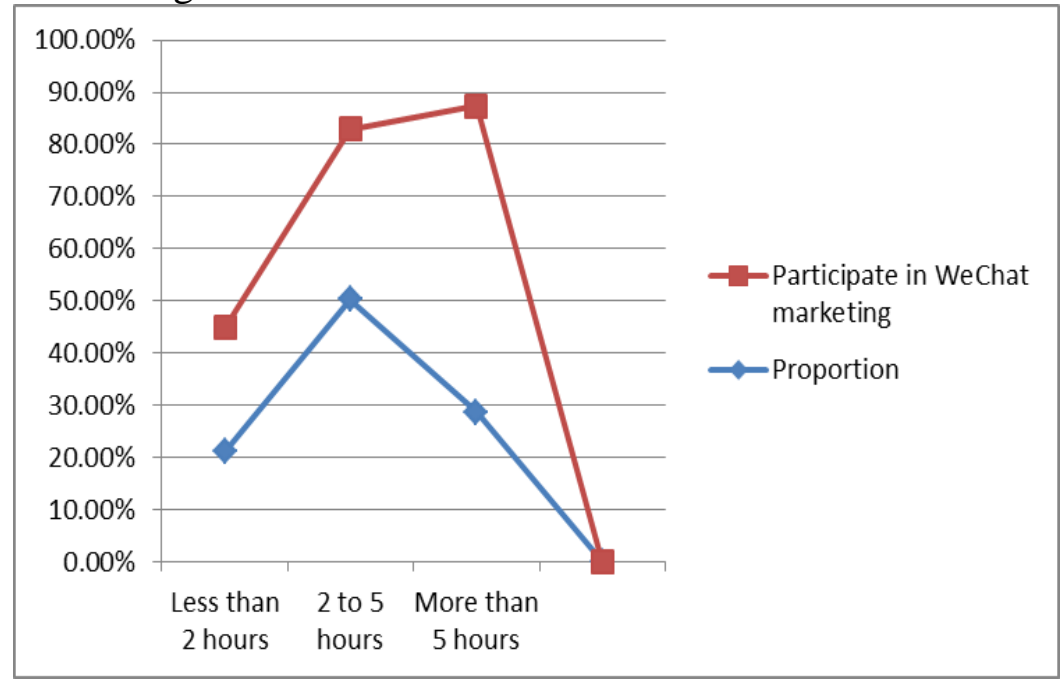

Fig. 4 WeChat day hours used compared with participation

\subsection{The influence of marketing the product type}

Enterprises through the WeChat marketing products are mainly concentrated in food specialties, cultural and entertainment, interpersonal relationships, clothing and accessories and five types of life services. As shown in Figure 5, we found that college students in the categories of food specialties and cultural and entertainment in the two categories of business information more. Can actually participate in the marketing activities of WeChat, it is a relatively high proportion of food products and clothing accessories, which is in line with the characteristics of the daily consumption of College students. 


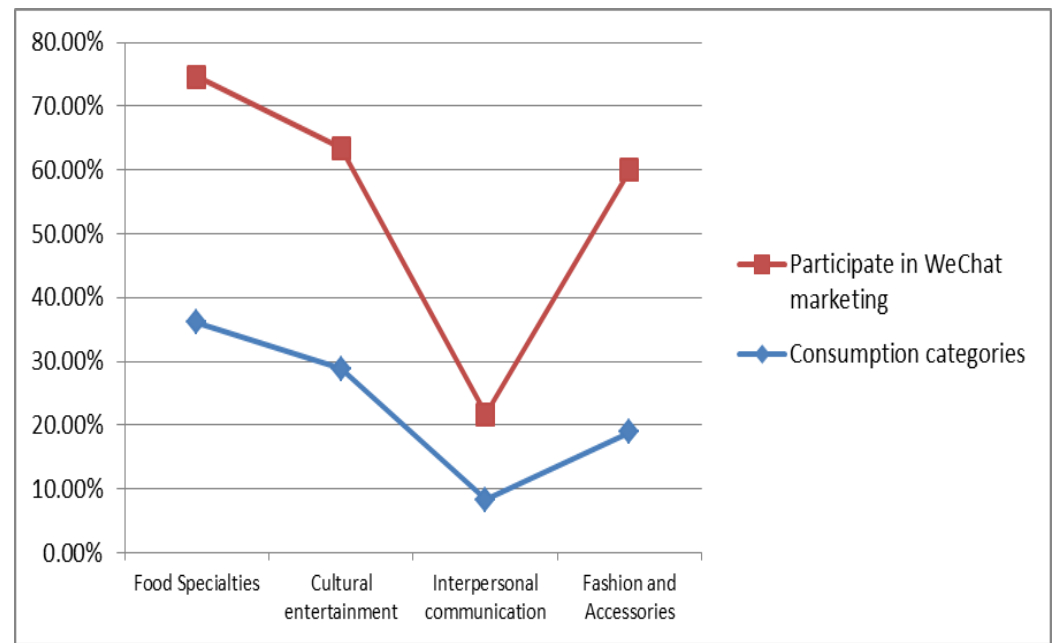

Fig. 5 The product type and participation contrast figure

\subsection{The influence of product price}

College Students' main economic source is provided by the family, so its consumption ability is very limited, so the price of the product in the consumer activity is bound to be great. 244 people participated in the WeChat marketing activities, the number of college students for consumer products 50-100 yuan pricing most, participation is also the strongest, the higher the price of their participation is low, as shown in Figure 6, therefore, if the enterprises carry out to college students as the object of WeChat marketing business, commodity pricing must fit college students the ability to accept and consumption ability.

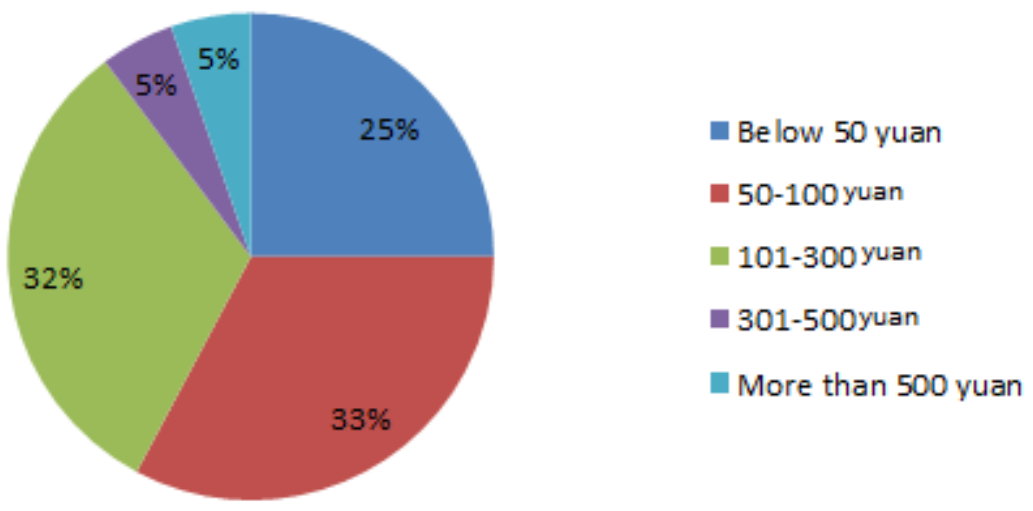

Fig. 6 Comparison of product price and participation

\section{Conclusion}

Enterprises in the process of WeChat marketing on the one hand to make the marketing information to the right people, on the other hand to avoid the excessive development of WeChat marketing of users, produces the negative effect of too much of a good thing. WeChat mall this a socialization, which is developed based on WeChat e-commerce system development also emerge, as long as consumers through WeChat platform, can realize the commodity inquiry, the choose and buy, experience, interactive, online ordering and paying the integration service mode. After all, these functions WeChat can suit the developer's original thought or to stay in the study of its user community, as a result, the user's attitude toward WeChat, college students attitude towards WeChat marketing activities and participation of the WeChat marketing activities can from a side reaction WeChat and WeChat does a marketing campaign in its opening up a road go further. 


\section{References}

[1] Xinfeng. Analysis on the current situation of College Students' WeChat marketing. News dissemination. Vol. 42 (2015) No. 10, p. 41-42.

[2] Yunbao Zhang, hangDanyang. O2O new model - Based on the investigation of WeChat marketing in the college students' market in Shenyang City. Guide of Sci-tech Magazine. Vol. 33 (2014), p. 134-135.

[3] Huanlan Fu. Investigation and Research on the marketing contact and usage of college students in WeChat. Electronic Commerce. Vol. 50 (2016) No. 5, p. 38-39.

[4] Weihong Si, Xiangyu Wang. Investigation and Research on the acceptance degree of the university students to WeChat. Modern business. Vol. 60 (2015) No.5, p. 279-280. 